\title{
The Role of Amateur Astronomers in Astronomy Education
}

\author{
By J.R. Percy \\ Erindale College, University of Toronto, Mississauga ON, Canada L5L 1C6
}

\section{What Is An Amateur Astronomer?}

Let us begin by defining "amateur astronomer". According to a dictionary, an amateur astronomer is "someone who loves astronomy, and cultivates it as a hobby". At IAU colloquium 98 (The Contributions of Amateurs to Astronomy), Williams (1988) discussed this issue at length. He proposed that, to be an amateur astronomer, one must be an astronomer - able to do astronomy with some degree of skill; he then defined an amateur astronomer as "someone who carries out astronomy with a high degree of skill, but not for pay".

Unfortunately, the word "amateur" has negative connotations to many people. This is partly because of the unfortunate choice of the word; "volunteer astronomers" might be a better choice. It is partly because there are indeed a few amateurs whose ideas and attitudes might be judged rather bizarre - but the same is true for some professionals. There might even be a hint of snobbery, especially in cultures in which qualifications (as opposed to ability) are paramount. Professionals certainly respect the contributions of the "superstars" of amateur astronomy: Frank Bateson, Robert Evans, Patrick Moore and the like. We tend to hold these people as examples, though very few amateurs are willing or able to contribute at this level. There are thousands of "rank-and-file amateurs" worldwide. They can and do contribute significantly to the advancement of astronomy.

I prefer to define amateur astronomer extremely broadly. In this case, their education, knowledge, skills at instrumentation, computing, observing, teaching and other astronomical activities could be anything from zero to $\mathrm{PhD}$ level in astronomy or a related field. Many amateur astronomers are professionals in other scientific or technical fields. When you think of it, there is a wide range of interests and abilities among professionals, or even in one professional at different points in his/her career. Some become amateurs when they retire. In some countries now, many undergraduate and graduate students in astronomy are taking jobs in other fields. We should strongly encourage all these people to continue to contribute to astronomy, as volunteers. It is also possible that a very capable and persistent amateur astronomer - such as Patrick Moore in the UK, and Terence Dickinson in Canada - can eventually establish a career in astronomy and become a professional! Amateur astronomers are united by one characteristic - their interest and enthusiasm for astronomy. Considering that there are at least ten times more amateurs than professionals, they are an ally which we should not ignore.

Almost every child is interested in astronomy, and many of them aspire to become an astronomer. They grow out of this phase of course, especially when they realize that the number of jobs in professional astronomy is limited. By recognising and valuing amateur astronomy, we can offer our students another option - choosing a different career, but continuing their interest and involvement in astronomy as an amateur. This may be an especially useful and realistic option in the developing countries, and in countries such as China and Russia where business careers are now much more lucrative than academic ones. 


\section{What Is Astronomy Education?}

Earlier in this meeting, I defined astronomy education by quoting Fraknoi (1996): he pointed out that astronomy education takes place, not only in the classroom, but in many informal environments as well. His point was addressed to professional astronomers and educators; for the purpose of the present paper, I will reverse Fraknoi's point. Amateur astronomers are accustomed to contributing to informal or public education but, in this paper, I want to point out that amateurs can contribute to formal or classroom education as well.

\section{The Contributions of Amateur Astronomers to Astronomical Research}

The contributions of amateur astronomers to research are well known, and were discussed at length at IAU Colloquium 98 (Dunlop and Gerbaldi (1988)):

- Comets: discovery, imaging, astrometry, photometry

- Variable Stars: discovery and photometry

- Novae and Supernovae: discovery and photometry

- Solar Astronomy: sunspots, solar flares, sudden ionospheric disturbances

- Meteors and Aurorae: systematic observation

- Instrumentation, Software and Computation: development and use

- Occultations: total and grazing; lunar, planetary and asteroidal

- Asteroids: discovery, astrometry and photometry

- Double Stars: measurement

- Eclipses: solar and lunar

Some fields are, of course, more fertile for significant contributions than others. These contributions have a significant impact on education. The discovery of comets such as Shoemaker-Levy 9, Hyakutake, and Hale-Bopp, have a profound effect on public interest in astronomy.

Students can also use amateur astronomers' data and techniques for a variety of projects. At this colloquium, I displayed a poster, with Mattei and Saladyga as coauthors, describing "Hands-On Astrophysics" - an education project of the American Association of Variable Star Observers. This project uses variable star data and observation to develop and integrate a wide range of skills in math, science and computing. Presently, it is targeted at high school students, but it can be used, with minor modification, at university level. It uses visual observations from the AAVSO's International Database, made primarily by amateur astronomers from around the world. It also uses the charts and techniques which have been refined by AAVSO observers, to enable the students to make measurements from the real sky.

The AAVSO hopes that this project will not only contribute to science education, but that it will also attract young people to amateur astronomy. The AAVSO and other such organisations have noted a decline in interest in serious amateur astronomy - at least in North America. The average age of AAVSO observers is increasing, and this does not bode well for the future.

My students use AAVSO data for projects (Percy et al. 1996). They also use data from an Automatic Photometric Telescope developed by amateurs Lou Boyd and Russ Genet (Percy and Attard 1992). Software written by amateurs is widely used by students. The techniques developed by amateur astronomers for the observation of the sun, moon, planets and other objects are the same ones used by students in their practical lab 
sessions, so that books such as the three-volume Compendium of Practical Astronomy (Roth 1994) are useful references for astronomers and teachers.

The majority of amateur astronomers are content to read about astronomy, or learn about it through other channels, or to be recreational sky observers. Some belong to clubs or larger associations; others pursue their hobby in a more independent way. Individuals, clubs, and associations of amateur astronomers can support astronomy and astronomy education in many other ways.

\section{Amateur Astronomers As Supporters Of Astronomy}

Amateur astronomers of all kinds provide grass-roots support for both research and education in astronomy. Many observatories and planetariums - including those in my city of Toronto - came about, in part, because of the efforts of amateurs. In many cases, the facilities were funded by generous contributions from amateur astronomers. The AAVSO, for instance, owes its existence to the generosity of Clinton B. Ford. This may be especially important in countries such as the developing countries, and the former Soviet Union, where there is little government funding for astronomy, but where former astronomers or astronomy students are now business people. At the risk of sounding mercenary: I think we should become aware of rich and influential people who have a special interest in astronomy. Their interest was usually sparked by some interaction with a professional or amateur astronomer, at a public lecture, star party, or other such event. This is a strong argument for public outreach, by both amateurs and professionals.

Another area of common concern to both astronomers and educators is light pollution. Amateurs, with their broad range of interest, training and experience, are often seen as "ordinary citizens" rather than as lobbyists, and carry considerable weight with local politicians

\section{Amateur Astronomers And Public Education}

When most people think of amateur astronomers' contributions to astronomy education, they probably think first of public education. This was certainly the main topic of discussion at IAU Colloquium 98. The list of possible contributions is a long one:

- TV and Radio Programs: Patrick Moore's monthly TV program is legendary. In my city of Toronto, a long-running series of programs on community cable TV was produced - very professionally - by local amateur astronomers.

- Newspaper and Magazine Articles: The largest-circulation newspaper in Canada has published a weekly astronomy column since 1981 by former amateur astronomer Terence Dickinson.

- Books: Patrick Moore and Terence Dickinson are prolific authors of books; one of Dickinson's books has recently been turned into a movie concept for director Steven Spielberg - an achievement which very few professionals have shared. In both the industrialised countries, and in countries with very few professional astronomers, amateurs often fill the need for public information about astronomy. Their writing skills are often as good as, or better than those of professionals, and they find it easier to write in non-technical language.

- Courses and Lectures: In most cities, the lectures organized by the local astronomy club are a rich resource for both the public, and for students with a special interest in astronomy. Many colleges, school boards, planetariums and museums, offer noncredit astronomy courses which are given by amateurs. The Astronomical League, the "umbrella organisation" of astronomy clubs in the US, has produced a useful booklet on 
how to organise a public lecture or course. (Astronomical League: 2112 Kingfisher Lane East, Rolling Meadows, IL 60008, USA; 73357.1572@CompuServe.com).

- Planetariums and Science Centres: Almost all of these facilities use amateur astronomers to organise star parties, and many use amateurs to present shows. In my city of Toronto, most of the original staff of the planetarium were local amateur astronomers.

- Public Observatories: These facilities are much more common in Europe than in North America. There are exceptions, and many North American public observatories came about through the efforts of the local astronomy club. In many public observatories, amateurs play an important role in scientific work, as well as in educational programs for students and the general public.

- Star Parties: Star parties in the parks are a popular and important activity of amateur astronomers; they enable people - both young and old - to get an "eyes-on" view of the universe. Amateurs assist at the weekly public programs of my university's David Dunlap Observatory, north of Toronto, as well as at the many events which they themselves organize.

- Displays: There are many venues where groups of amateur astronomers can set up demontrations and displays, and talk informally and enthusiastically with the general public. My local astronomy club organizes such events in libraries, in shopping malls, in museums and science centres, and at the annual Canadian National Exhibition which attracts almost two million visitors during a three-week interval each year.

- Electronic Resources: Amateurs, who are often skilled at computer science and related fields, have been quick to set up Web sites of interest to both students and the public.

I want to make special mention of Astronomy Day (or Week), a program of the Astronomical League. The Astronomical League sets and promotes Astronomy Day in North America, and have produced a useful handbook for organising a successful Astronomy Day program. This handbook is obtainable, at modest cost, from Gary Tomlinson, Public Museum of Grand Rapids, 272 Pearl St. NW, Grand Rapids, MI 49504, USA.

In Toronto, Astronomy Day is a collaborative program of two universities, a planetarium, a science centre, and the local astronomy club - with the local astronomy club taking the lead. This year, we added a teachers' workshop to the program, with Professor Michele Gerbaldi as the very special guest. This workshop was co-sponsored by the local science teachers, science co-ordinators, and teachers' union, so it brought additional partners into the astronomy education sphere.

Astronomy Day (or its equivalent) is celebrated in many countries around the world, though not necessarily on the same date. I would like to see the IAU, through Commission 46 , officially support the concept of Astronomy Day, with the detailed circumstances of the celebration to be determined by the local organisers.

\section{Amateur Astronomers and Formal Education}

Amateur astronomers support astronomy in the schools and universities, but usually "at a distance". In the US, the Astronomical League sponsors the National Outstanding Young Astronomer award. Astronomy clubs in Canada offer scholarships and awards to outstanding students; they provide judges for science fairs, and speakers for special programs at schools. They may even do class visits, or arrange star parties for students. But their relationship with the teacher and students is not an ongoing partnership. To achieve that, amateur astronomers must understand the nature of teaching and learning, and the realities of the classroom environment. The teacher must understand the 
background and motivation of the amateur astronomer, and not feel intimidated by their own lack of knowledge of astronomy.

\section{Amateur Astronomers and Elementary School Education}

Two of the main problems of elementary school astronomy education worldwide are (i) the lack of teacher training and confidence; and (ii) the problem of arranging observing sessions, especially at night. Both these problems can be overcome through partnerships between teachers and amateur astronomers. Bennett, elsewhere in this book, describes an exemplary program: the Astronomical Society of the Pacific's Project ASTRO. The keys to success in this and other such programs are: (i) effective orientation and training of both the teacher and the amateur, and (ii) development of resources, such as books and slides, to support the program. The external evaluations of Project ASTRO were very positive. They showed, among other things, that amateur astronomers were even more successful than professional astronomers in forming successful partnerships with teachers.

\section{Amateur Astronomers and Secondary School Education}

At the secondary level, the problems of teacher training and confidence are less, but the amateur astronomer (or his/her club) can still play an important role by providing access and instruction in the use of telescopes, either in the school or in some other location. Another interesting connection is the fact that, according to the paper of Sadler and Luzader (1990) at IAU Colloquium 105 in Williamstown, the majority of teachers of astronomy in US secondary schools considered themselves to be amateur astronomers! Clearly, then, by supporting amateur astronomy, we are supporting astronomy education!

\section{Amateur Astronomers and University Education}

University astronomy education is normally seen as the preserve of professional astronomers, and that is certainly the case in major research universities. But at smaller colleges in North America, and at universities in the developing countries, amateur astronomers provide access and instruction in the use of telescopes. I think of the contributions of Eduardo Parini in Paraguay, who made his private observatory available to the IAU Visiting Lecturer Program. In the UK, some advanced amateur astronomers serve as tutors at The Open University and, in at least one college in the US, they are brought in as visiting lecturers in introductory astronomy courses. If they are interested and capable, they may even serve as instructors, especially if there are no professional astronomers available. After all, the "hands-on" approach is a very effective one in university, and amateur astronomers may be best suited to this approach.

\section{Summary}

I have tried to make several points, most of which are probably obvious. The most important one is that amateurs are a large, diverse, enthusiastic and skilled group of people who can relate very well to students, teachers, and the general public. We should respect them, cultivate them, train them, learn from them and work with them in our common goal to increase awareness, appreciation and understanding of the universe. I have worked with amateur astronomers for 35 years, through the Royal Astronomical 
Society of Canada, the American Association of Variable Star Observers, the Astronomical Society of the Pacific, and other organisations, and I count amateurs among my best colleagues and friends.

In order for this to happen, there have to be links between professional and amateur astronomers, and other educators - particularly at the local level. In June 1995, a major conference on astronomy education was held at the University of Maryland (Percy 1996). It identified, as a high priority in astronomy education, the formation of coalitions and networks of astronomy educators, who could learn about the best available ideas, resources and materials for astronomy education. In my city of Toronto, such a coalition has existed because of the organisation of Astronomy Day each year. In 1995, the coalition was mobilized to deal with a sad event: the closing of the McLaughlin Planetarium - one of the world's major planetariums. We hope that the quick and strong response of professional and amateur astronomers, teachers, and people from every walk of life, will lead to the refurbishment and reopening of the planetarium. It was certainly a sign that interest in astronomy is shared by a wide segment of our population.

\section{REFERENCES}

Dunlop, S. \& Gerbaldi, M., 1988 Stargazers: The Contributions of Amateurs to Astronomy, Berlin, Springer-Verlag

Fraknor, A., 1996, Astronomy Education: Current Developments, Future Coordination ASP Conf. Series, Vol. 89, 9-25.

Mattei, J.A. Et AL., 1996, Astronomy Education: Current Developments, Future Coordination, ASP Conf. Series, Vol. 89, 247-248.

Pasachoff, J.M. \& Pency, J.R., 1990, The Teaching of Astronomy IAU Colloqium 105, Cambridge, Cambridge University Press.

PerCY, J.R., ed. 1996, Astronomy Education: Current Developmen, Future Coordination, ASP Conf. Series, Vol. 89.

Percy, J.R. \& ATtaRd, A., 1992, PASP 104, 1160-1163.

Percy, J.R., Desjardins, A., Yu, L. \& Landis, H.J., 1996, PASP 108, 139-145.

Roth, G., ed. 1992, Compendium of Practical Astronomy, Berlin, Springer-Verlag.

Sadler, P.M. \& Luzader, W., 1990, The Teaching of Astronomy, IAU Colloquium 105, Cambridge, Cambridge University Press, 257-276.

WILliams, T.R., 1988, Stargazers: The Contributions of Amateurs to Astronomy, Berlin, Springer-Verlag, 24-25. 